\title{
Expansion of Area under Rubber Plantation and its Distribution in Tripura, India
}

\author{
Raju Debbarma ${ }^{\dagger}$ and Dr. S.Purkayastha ${ }^{\hat{i}^{*}}$
}

\section{Abstract}

Rubber plantation was introduced in the state of Tripura in 1963. This state is emerging as an important producer of natural rubber in India, second only to Kerala. This research attempts to assess the role of rubber plantation as a policy intervention by the state to usher in the development of the marginalised population of Tripura. It examines the expansion of the area under rubber plantation and its present distribution pattern in the state. In doing so, it attempts to discuss and analyse the factors responsible for such expansion, distribution and identification of the core areas of concentration of rubber plantation through the use of secondary data, which has been analysed using concentration index.

Keywords: Rubber Plantation, Growth, Distribution, Concentration Index, Tripura

\footnotetext{
${ }^{+}$Research Scholar, Department of Geography, North-Eastern Hill University, Shillong-793022, Meghalaya, India, Email: rajudbarma@gmail.com

ÎFaculty, Department of Geography, North-Eastern Hill University, Shillong-793022, Meghalaya, India

*Corresponding Author, Emails: subratashg@yahoo.com and spurkayastha@nehu.ac.in

C2019 Debbarma \& Purkayastha. This is an Open Access article distributed under the terms of the Creative Commons Attribution License (http://creativecommons.org/licenses/by/2.0), which permits unrestricted use, distribution, and reproduction in any medium, provided the original work is properly cited.
} 


\section{Introduction}

Rubber plantation has been playing a pivotal role in the development of the marginalised section in Tripura, a state located in the North East of India. But little is known about the growth of rubber, its development and expansion in the state. This research aims to examine the expansion of area under rubber plantation, and its present distribution pattern in the state. First, though, it is important to shed light on rubber plantation in other economies of the world.

Over the past half century, countries of the South and Southeast Asia are witnessing a major shift from predominantly subsistence agriculture including shifting cultivation to industrialised economies. This has led to commercialisation of agriculture resulting in the expansion of cash crops including several tree based crops like rubber, coffee, cashew nuts, etc. leading to the replacement of the food crops (East-west Center, n.d). The main natural rubber production zone is concentrated between $15^{\circ}$ North and South of the Equator, which includes both Southeast Asia and South Pacific countries like Malaysia, Indonesia, Thailand, Sri Lanka, South India, Cambodia, Vietnam, Philippines, PapuaNew Guinea and Southern China. Rubber plantations have also been established in Central and West Africa (Congo, Cameroon, Ivory Coast, Liberia), while in tropical America, it is concentrated over a small area between $10^{\circ}$ North and South of the Equator. However, at present rubber plantations are found as far as $25^{\circ}$ North (Yunnan Highlands, China), and $21^{\circ}$ South of the equator, that is extending up to Brazil (Verheye, 2010). Besides the traditional rubber growing areas of southern Thailand, south-eastern Vietnam and southern Myanmar (Fox and Vogler, 2005; Fox and Castella, 2013), rubber plantation is spreading to the nontraditional areas of Laos, Cambodia, northwest Vietnam, northeast Thailand and Yunnan province of China (Li and Fox, 2011; Fox and Castella, 2013). The expansion of area under rubber plantation has also been increasing rapidly in Menglun Township of Southwest China
(Liu et al., 2006) and Xishuangbanna region in southwest China (Chen et al., 2016).

Natural rubber production in the world is dominated however, by Asia, particularly the south-east Asian countries. The biggest natural rubber producer in the world is Thailand followed by Indonesia while Malaysia lost its role of being the biggest producer of natural rubber as the land under rubber plantations are being converted into oil palm plantation mainly due to the shortage of labour, high labour costs and the growing demand for oil palm (Verheye, 2010).

It is interesting to note that by 2050 , the area under rubber plantation in the mountainous region of south and southeast Asia comprising of Cambodia, Laos, Myanmar, Thailand, Vietnam and China's Yunnan province is predicted to increase fourfold (Fox et al., 2014). This is leaving its impact not only on the environment but also on the social, economic and political setup of the society. It is observed that rubber plantation often leads to local level climate change, deforestation, triggering landslides, loss of soil quality, sedimentation and disruption of streams and increase in carbon emission (Fox et al., 2014). The increase in area under rubber plantation in southwest China has been at the expense of forest areas as well as fallow fields/shifting agriculture (Liu et al., 2006; Fu et al., 2009; Chen et al., 2016). In Xishuangbanna region of southwest China, the expansion of area under rubber plantation towards the higher elevations, steep terrain and into forest tracks has created a serious threat to biodiversity and environmental services (Chen et al., 2016). Field-based studies from Bukit Tarek watershed located in Malaysia (Noguchi et al., 2003) suggest that establishment of rubber plantation results in considerable topsoil loss and soil compaction leaving its impact on the hydrology of the area. Area under rubber plantations is expanding especially in the developing economies in the tropical parts of the world due to the higher economic returns from this plantation. The traditional forms of land-use are changing to a more intensive commercial agricultural practices. The factors responsible for 
this change can be attributed to population growth which makes shifting cultivation unsustainable as land men ratio declines. The expansion of road networks, which links the markets make it easier for farmers to purchase the inputs and sell their produce, thereby, increase the demand for natural rubber. Government sponsored crop substitution programme as the national governments have accelerated land-use changes by introducing explicit policies to replace traditional shifting cultivation systems with other forms of land use including permanent cultivation of crops like rubber plantation (Fox et al., 2014). A similar situation is also observed in the Northeastern states of the Indian Republic comprising of the states of Arunachal Pradesh, Assam, Nagaland, Meghalaya, Manipur, Mizoram, Tripura and Sikkim (Figure 1), where small communities living in close proximity to nature, practising slash and burn or shifting cultivation locally known as jhum cultivation have been discouraged from practicing their traditional agriculture with the plea that this traditional practice of jhum cultivation is highly unsustainable. Due to high population growth in these states, the jhum cultivation cycle here is reducing, resulting in the absence of secondary forest cover, accelerating the problem of deforestation leading to soil erosion, degrading the land resource, which is adversely affecting these small communities, who already lack socio-economic development and are often plagued by severe poverty. The state government has thus intervened to change the traditional agricultural land-use system to more market-oriented commercial agriculture by introducing rubber plantation in spite of its environmental drawbacks. Like the Chinese government (Liu et al., 2006; Fox and Castella, 2013; Fox et al., 2014); the state government here also considers rubber plantation as a secondary forest cover. Hence expansion of the area under rubber plantation is taken as an expansion of forest cover. In the state of Tripura, rubber plantation has made positive contributions in afforesting/restoring the denuded hillocks and degraded forests due to frequent jhum cultivation and indiscriminate felling of trees (Krishnakumar and Meenattoor, 2003). But unlike other tropical southeast Asian countries, e.g. Malaysia where rubber plantation is encouraged even in forested tracks leading to forest clearance and associated forest loss (Abdullah and Nakagoshi, 2006); in India, the government has banned rubber plantation in forested tracks - such as reserve forests as it needs to be preserved.

It is interesting to note that rubber plantation is not new in India as it was initially introduced in the southern states of present Tamil Nadu and Kerala (at present known as the traditional rubber growing area of India) by the British during the colonial period, as the climate, physiography and soil conditions are ideal for rubber plantation. The native Indians provided further cheap labour., Consequently vast tracks of forest were cleared here for setting up rubber plantation to feed the industries of Great Britain. After India's independence, the next phase of expansion of rubber plantation has been initiated where the focus is on the non-tradition areas comprising the northeastern states of India as the climate, soil and physiography here are conducive for rubber plantation. Unlike the colonial power (as the basic objective of the colonial power was exploitative, mainly guided by profit motive, exploiting cheap labour and sucking out the raw material to feed the demand in Europe), rubber plantation in northeast India has been introduced as a development programme to check de-forestation, soil erosion and rehabilitate the economically and socially marginalised communities who are still in the process of development, practicing jhum cultivation characterised by lower socioeconomic development. The northeastern state of Tripura has emerged as an important producer of natural rubber in the country, second only to Kerala. Studies (Joseph et al., 2010; Sharma et al., 2011) suggest that rubber plantation has helped in integrating the marginalised section into the mainstream development process through this policy intervention.

A brief history of rubber plantation in Tripura suggest that in 1963, the first rubber plantation 
was introduced here by the Tripura Forest Department on a trial basis as part of afforestation programme for soil conservation measures in the degraded forest land caused by jhum cultivation practiced by the scheduled tribes (ST) population (Jacob, 2000 cited by Chaudhuri et al., 2013; Viswanathan and Bhowmik, 2014). This trail proved successful, this motivated the Tripura Forest Department to increase the area under rubber plantation. As rubber is a new commercial crop, it was initially rejected by the various tribes living here. However, the economic importance and benefits of rubber trees were soon realised especially after the rubber trees started giving returns with the commercial tapping of latex and processing of rubber that started around 1971-72 (Bhowmik, 2006; Viswanathan and Bhowmik, 2014). Rubber plantation thus hogged the limelight as a tool for not only integrating the marginalised population within the ambit of mainstream development but winning over the shifting cultivators (jhumias) to settled agriculture. Consequently, the state government through various government agencies, viz. Tripura Forest Development and Plantation Corporation Limited (TFDPCL), Tripura Rehabilitation and Plantation Corporation Limited (TRPCL); the tribal/scheduled caste welfare department in collaboration with the Rubber Board, encouraged office of the Tripura Tribal Areas Autonomous District Council (TTAADC) and office of the Sub-Divisional Magistrates/Block Development Officer (SDM/BDO) (Bhowmik, 2006; Joseph et al., 2010; Viswanathan and Bhowmik, 2014) for initiating expansion of area under rubber plantation in the state in order to rehabilitate the economically and socially marginalised groups that is, the jhumias, landless and marginalised farmers of the state. The private sector and individual owners have also been encouraged to set up rubber plantation, and they too have shown a keen interest in rubber plantation as it brings in high returns (Gupta, 1990a). Consequently, the area under rubber plantation in Tripura has been expanding due to the favourable agro-climatic conditions coupled with physiographic condition characterised by undulating topography marked with small hillocks locally termed as tillas having gentle slope with soil composition ideal for rubber trees (Gupta, 2000; Maithani, 2005). The encouragement from the government agencies alongside the acceptance of rubber as an important commercial crop by the local population (Sarkar, 2011) has made Tripura the largest producer of natural rubber in Northeast India. The Rubber Board has declared Tripura the 'Second Rubber Capital of India' next to Kerala (Viswanathan and Bhowmik, 2014; Directorate of Economic and Statistics Planning Department (DESPD), 2016). In the light of this backdrop, this research attempts to assess the expansion of area under rubber plantation and its present distribution pattern in the state of Tripura without emphasising on the environmental concerns associated with rubber plantation.The next section describes the study area, followed by the methods section.

\section{Study Area}

Tripura, a landlocked state is located in the southwestern part of northeast India (Figure 1) and the state holds a strategic position bounded in three directions by Bangladesh. The total geographical area of the state is 10, 486 sq.km (Census of India, 2011). Over 60 per cent of the state's area is covered by forest (Human Development Report, 2007). The topography consists of hills and valleys, while the high lands are suitable for rubber plantation, the valleys are ideal for paddy cultivation. About 100 thousand hectares (ha) of the state's geographical area is earmarked for rubber plantation (Bhattacharyya, Sehgal and Sarkar, 1996; Bahuguna, 2005, cited by Bhowmik, 2006). As per 2011 census, Tripura is home to 36, 73, 917 persons of which $11,66,813$ persons (31.8 per cent) consists of Scheduled Tribes (ST) population. There are nineteen ST communities living here. They are- Tipra/Tripuri/Tripura, Reang, Jamatia, Noatia, Uchai, Lushai, Mog, Kuki, Halam, Chakma, Garo, Khasi, Bhutia, Lepcha, Bhil, Munda, Orang, Santal and Chaimal. About 73.8 per cent of the total population inhabits the rural area dominated by the ST population (Census of India, 2011). The state reports a high 
incidence of poverty, low per-capita income, low capital formation, inadequate infrastructure facilities, geographical isolation, and lack of communication, insufficient exploitation and use of resources, little progress in the industrial field and high rate of unemployment. To usher in the much-needed economic development of especially the weaker sections of the society, the state government has introduced a variety of plantation crops including rubber. Among the principal crops in the state, and as already mentioned above, rubber plantation is ranked second in coverage of area and production after rice (DESPD, 2016).

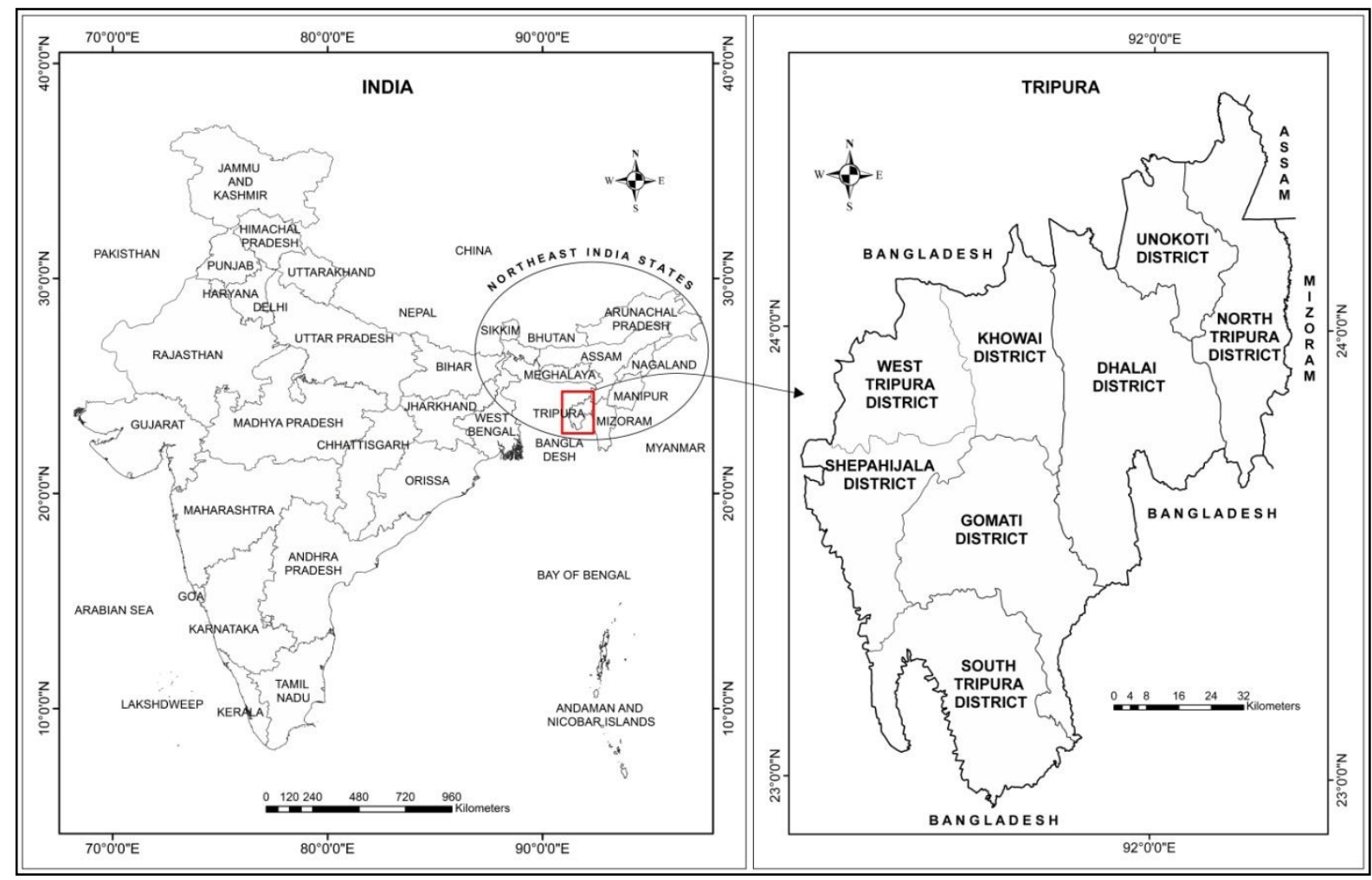

Figure 1: Location Map of the Study Area

Source: Survey of India, n.d.; Directorate of Land Records and Settlement, 2016.

\section{Materials and Methods}

The present study is based mainly on secondary sources. Secondary data has been collected from the Rubber Board, books, journals, reports, websites, etc.

The annual growth rate and decadal growth rate of the area under rubber plantation have been computed by 'arithmetic rate of growth' and 'annual compound rate of growth' (Hassan, 2005). To analyse the trend in the expansion of area under rubber plantation in the state from 1972-73 to 2015-16 (continues data from 196364 to 1971-72 are not available) time series analysis have been computed by the help of ' 3 yearly moving average' (Gupta, 1990b). The district wise distribution of the area under rubber plantation in the state have been analysed with the help of 'concentration index'
(Hassan, 2005). The formula of the concentration index is as follows:

$C l=(P / \nabla P) /(A / \nabla A)$

Where,

$\mathrm{Cl}=$ Concentration Index

$P=$ Actual rubber plantation area of the $i^{\text {th }}$ district

$A=$ Actual area size of the $i^{\text {th }}$ district

$\nabla P=$ Average rubber plantation area of the district in the state

$\nabla A=$ Average area size of the district in the state 
The district wise concentration of area under rubber plantation has been further mapped with the help of ArcGIS 10.3 software.

\section{Results and Discussion}

\section{The Growth of the Area under Rubber Plantation in Tripura}

The area under rubber plantation in Tripura in 1963-64 was only 8 ha (Das, 2014) which has

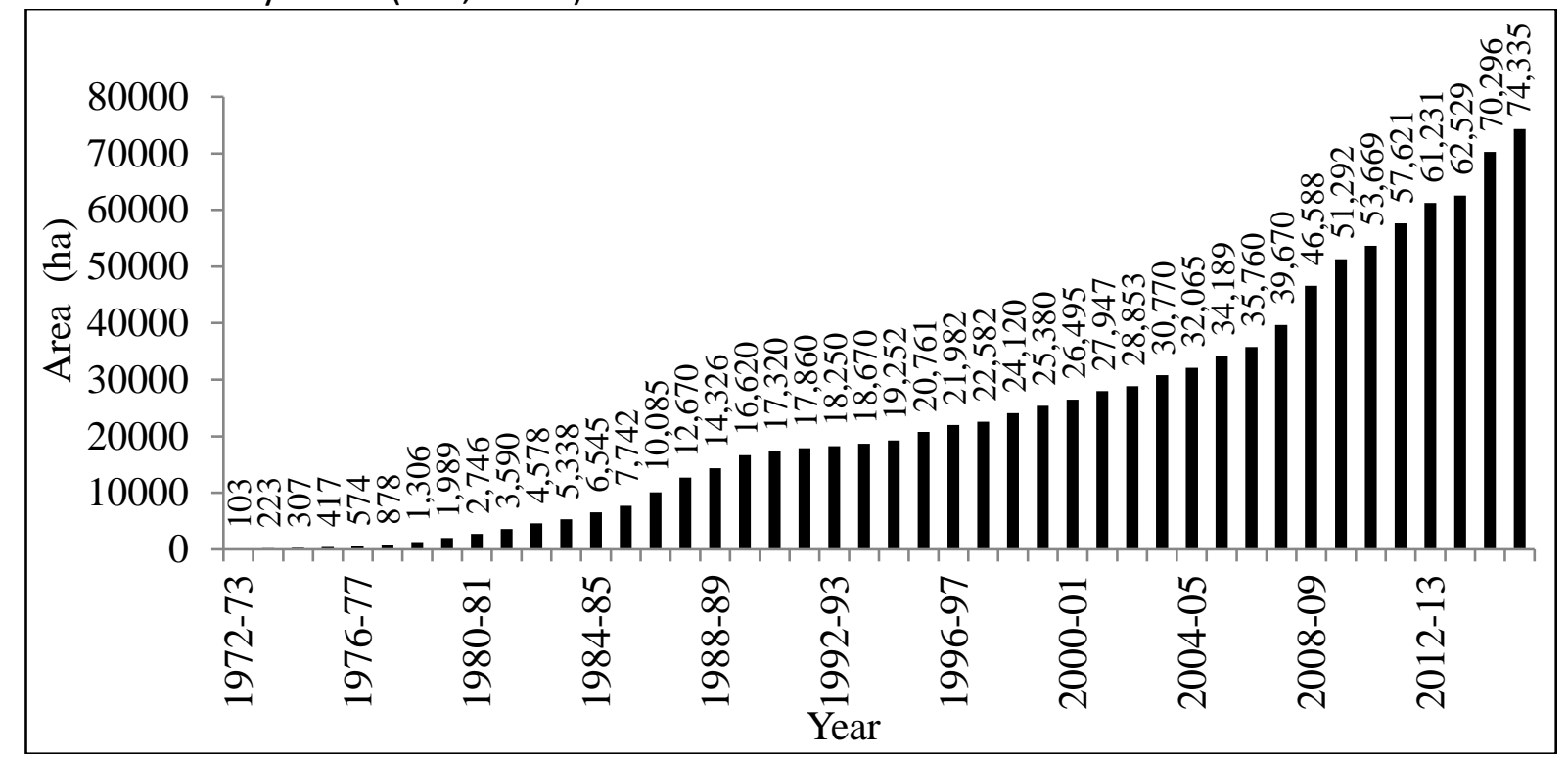

Figure 2: Total Area under Rubber Plantation in Tripura (1972-73 to 2015-16). Source: Rubber Board, 2016; Centre for Development Studies (CDS), n.d.

The area under rubber plantation in the state has continuously but at a declining rate with a been increasing continuously. Figure 3 indicates fluctuating trend (also see Table 2). From 1972the trend in the annual growth rate of the area 73 to 2015-16, the area under rubber plantation under rubber plantation from 1972-73 to 2015- in the state has been increasing at an average 16. The figure suggests that the area under growth rate of 18.05 per cent per year. rubber plantation in Tripura has been increasing

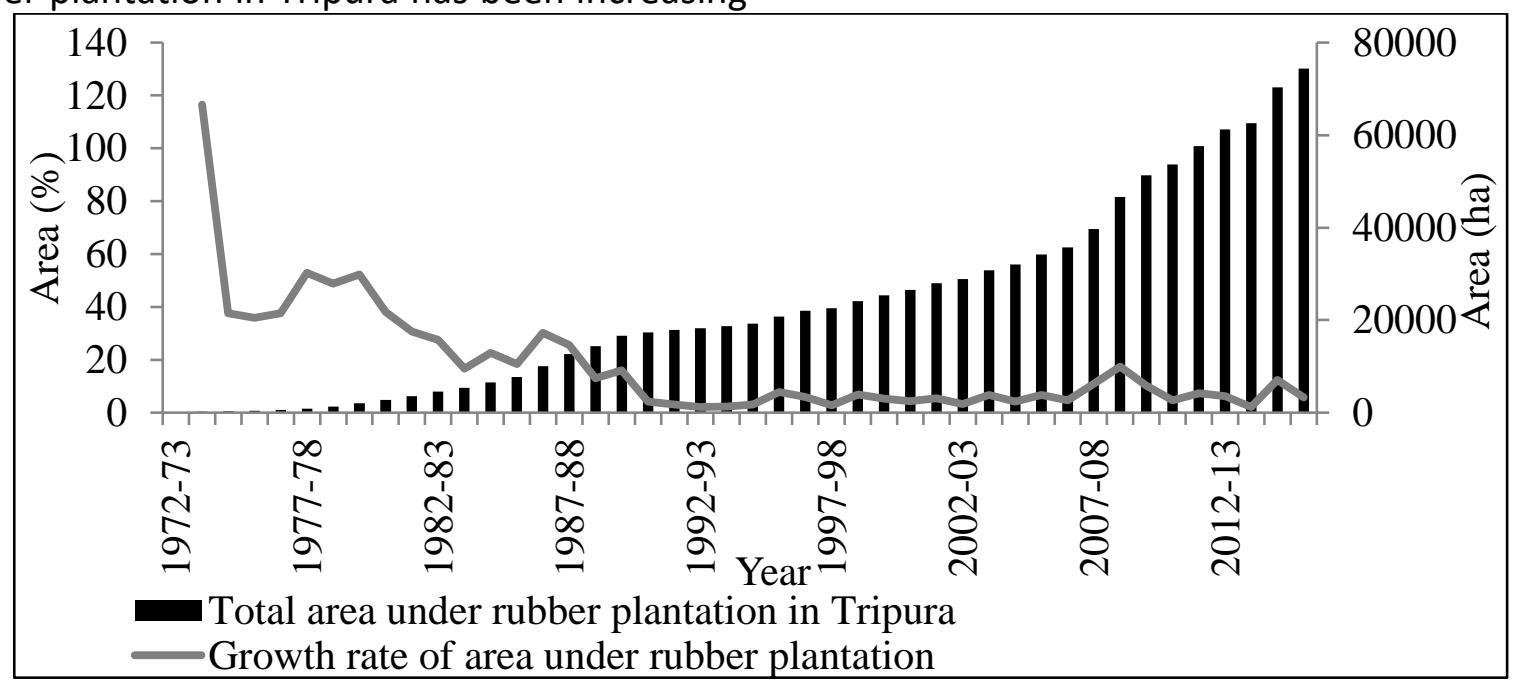

Figure 3: The Growth Rate of the Area under Rubber Plantation in Tripura (1972-73 to 2015-16).

Source: Rubber Board, 2016; CDS, n.d (Growth Rate of the Area under Rubber Plantation Computed by the Authors). 


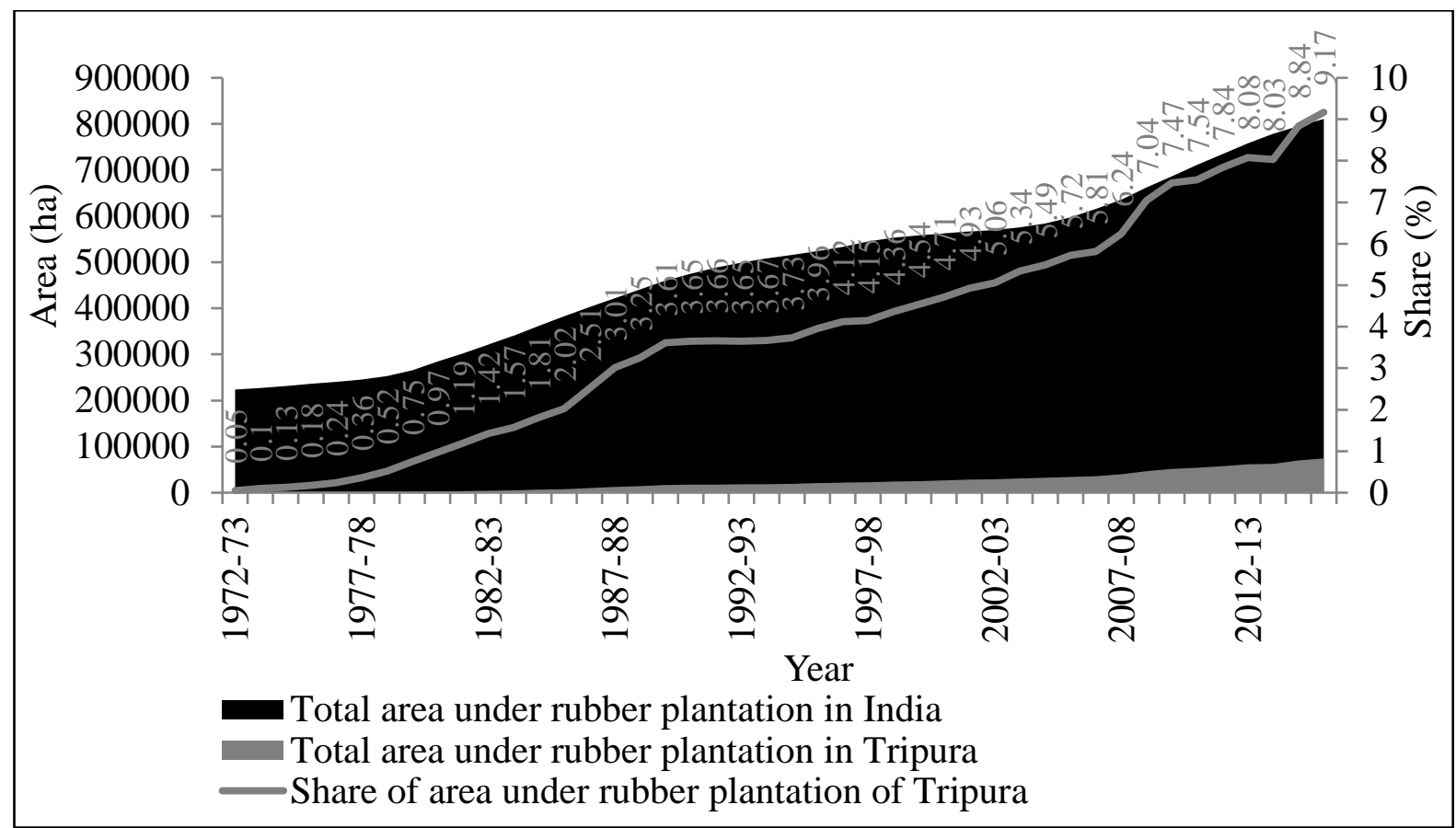

Figure 4: Share of the area under rubber plantation of Tripura to the total area under rubber plantation of India. Source: Rubber Board, 2016; CDS, n.d. (Share of the Area under Rubber Plantation Computed by the Authors).

Figure 4 depicts the share of area under rubber plantation of the state to the total area under rubber plantation of India. It is observed from the figure that the share of area under rubber plantation in the state geared-up from the early 1980s; this is attributed to the introduction of cash subsidy in rubber plantation by the Rubber Board around 1980s to encourage rubber plantation throughout the non-traditional rubber growing states of northeast India especially Tripura. The second major expansion in the share of area under rubber plantation in Tripura has been observed from the 1990s onwards which continues till 2006-07. After 2007, the share of area under rubber plantation in the state started increasing rapidly till 2012-13. However as observed, the share slightly declines in the year 2013-14 but regains back again in 2014-15 (also see Table 1). The main reason for the decline in the share of area under rubber plantation in the state in comparison to the total area under rubber plantation of India during the year 201314 can be attributed to the increase in area under rubber plantation in other rubber growing states of India.
The continuous expansion of area under rubber plantation in the state of Tripura is mainly due to the following reasons:

- The introduction of cash subsidy by the Rubber Board around the 1980s to expand the area under rubber plantation throughout the rubber growing states of northeast India (Viswanathan and Bhowmik, 2014).

- Increase in the prices of natural rubber owing to economic reforms and succeeding industrial spurt experienced by the country as a whole and the state in general which attracted a large number of private initiatives especially around 1994 and 1995 as private parties invested in rubber plantation (Viswanathan and Bhowmik, 2014).

- The revival of demand for natural rubber in the international market from 2001onwards soon after the depression which was experienced around the 1990s. This renewed the interest among the private and individual owners to invest in rubber plantation; consequently the area under rubber plantation 
increased (Viswanathan and Bhowmik, 2014).

- The implementation of rehabilitation programme through rubber plantation scheme for the marginalised section of people in the state by the state government agencies has also played an essential role in the expansion of area under rubber plantation (Bhowmik, 2006; Joseph et al., 2010; Viswanathan and Bhowmik, 2014).

It is observed that out of the 100 thousand ha of the state's geographical area earmarked for rubber plantation, at present 74.34 per cent (74,335 ha) of this area has come under rubber plantation indicating that around 25,665 ha (25.665 per cent) of area earmarked for rubber is still available for further cultivation of rubber trees in the state. Thus, there is scope for further expansion of the area under rubber plantation in the state.

\section{Nature of Growth of Area under Rubber Plantation in Tripura}

The introduction of rubber plantation in Tripura at present has crossed approximately 53 years, roughly corresponding to about five decades. An assessment of the decadal growth of area under rubber plantation in the state of Tripura suggests the following:

- By the end of the first decade (1963-64 to 1972-73), the area under rubber plantation was 103 ha indicating a compound annual growth rate (CAGR) of 28.67 per cent. In this decade, the expansion of area under rubber plantation had been mainly initiated by the Tripura Forest Department as a soil conservation measure in the degraded forests land caused due to jhum cultivation and illegal felling of trees (Mohanakumar, 2013)

- By the end of the second decade (197374 to 1982-83), the area under rubber plantation was 4,475 ha suggesting a CAGR of 35.28 per cent, signifying a faster growth in comparison to the previous decade. The expansion of the area under rubber plantation during this decade was further initiated through a rehabilitation programme under the TFDPCL (Mohanakumar, 2013).

- By the end of the third decade (1983-84 to 1992-93) the area under rubber plantation was 13,672 ha, recording a CAGR of 13.08 per cent, suggesting slower growth in comparison to the previous decade. In this decade, the expansion of area under rubber plantation was initiated through the rehabilitation programme by the TFDPCL and the TRPCL (Mohanakumar, 2013).

- By the end of the fourth decade (1993-94 to 2002-03) the area under rubber plantation was $10,603 \mathrm{ha}$, and the CAGR was 4.45 per cent suggesting a further slowing down of the growth in comparison to the previous decade. The expansion of the area under rubber plantation during this decade was mainly launched through rehabilitation programme known as Block Planning Scheme (BPS) integrated and implemented jointly by the Rubber Board and the Tribal Welfare Department functioning under the state government (Mohanakumar, 2013).

- By the end of the fifth decade (2003-04 to 2012-13), the area under rubber plantation was $32,378 \mathrm{ha}$, and the CAGR was 7.12 per cent suggesting a slightly higher growth in comparison to the previous decade. The expansion of the area under rubber plantation during this decade was initiated mainly by the private sector and individual owners.

\section{Annual Gain in the Area under Rubber Plantation and its Trend in Tripura}

Figures $5 \mathrm{a}$ and $5 \mathrm{~b}$ suggest the annual gain in the area under rubber plantation and its trend ( 3 yearly moving average) in the state for roughly over a period of four decades.

Figure 5a indicates that around the 1970s, the gain in area under rubber plantation was less than 500 ha/year and was lowest in the year 1974-75, when the gain in area under rubber plantation was as low as 84 ha, this can be 
attributed to the fact that in the initial period of launching of the rehabilitation programme, the jhumias and other marginalised population were slightly apprehensive about this programme. However, by the mid-1980s, this programme picked up as suggested by the gain in the area under rubber plantation that was more than 1,000 ha/year. However, it is from the present century that area under rubber plantation in Tripura suggests a substantial increase, reaching two peaks, that is, 2008-09 (annual gain of the area is 6,918 ha) and 2014-15 (annual gain of the area is $7,767 \mathrm{ha}$ ). This suggests that the rubberbased rehabilitation programme has been quite a success in the state and the area under rubber plantation is expanding.
A three-yearly moving average trend line demonstrates that the gain in the area under rubber plantation in Tripura in the initial phase was slow, which continued till 1984-85. After 1985 , the area under rubber plantation suggests an upward trend; however, this declined by the early 1990s. From the mid-1990s onwards to 2005-06, the trend line fluctuates, indicating that the gain in the area under rubber plantation is also swinging. From the year 2006, the trend line is suggestive of an increase in the area reaching its peak in 2008-09. From 2010 till 2012-13, the trend line is declining but from the year 2013-14 onwards the trend line is suggestive of further gain in the area under rubber plantation (Figure $5 \mathrm{~b}$ and please refer to Table 2 as well).

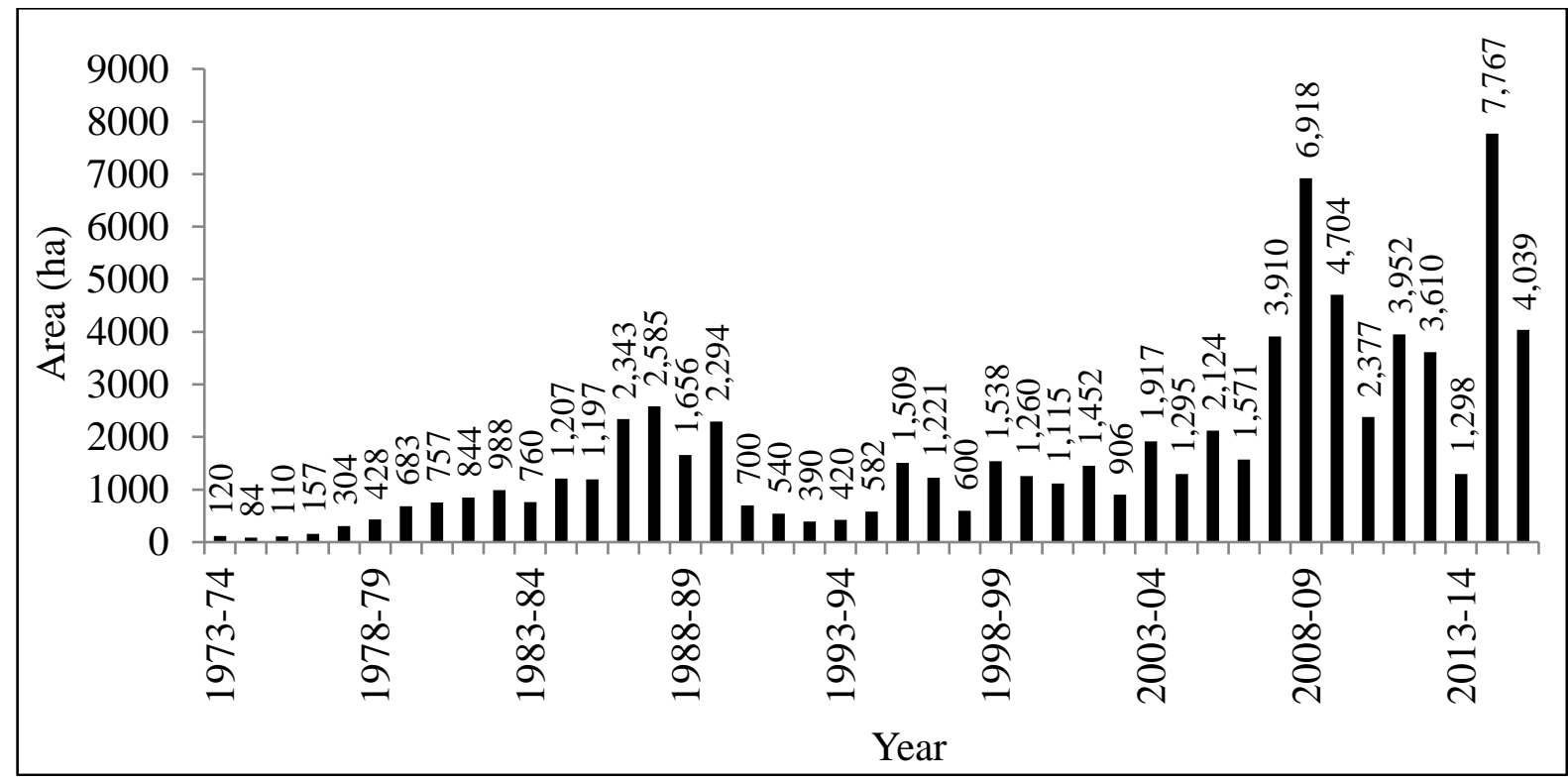

Figure 5a: Annual Gains in the Area under Rubber Plantation in Tripura (19973-74 to 2015-16). Source: Rubber Board, 2016; CDS, n.d (Annual Gain in the Area under Rubber Plantation Computed by the Authors). 


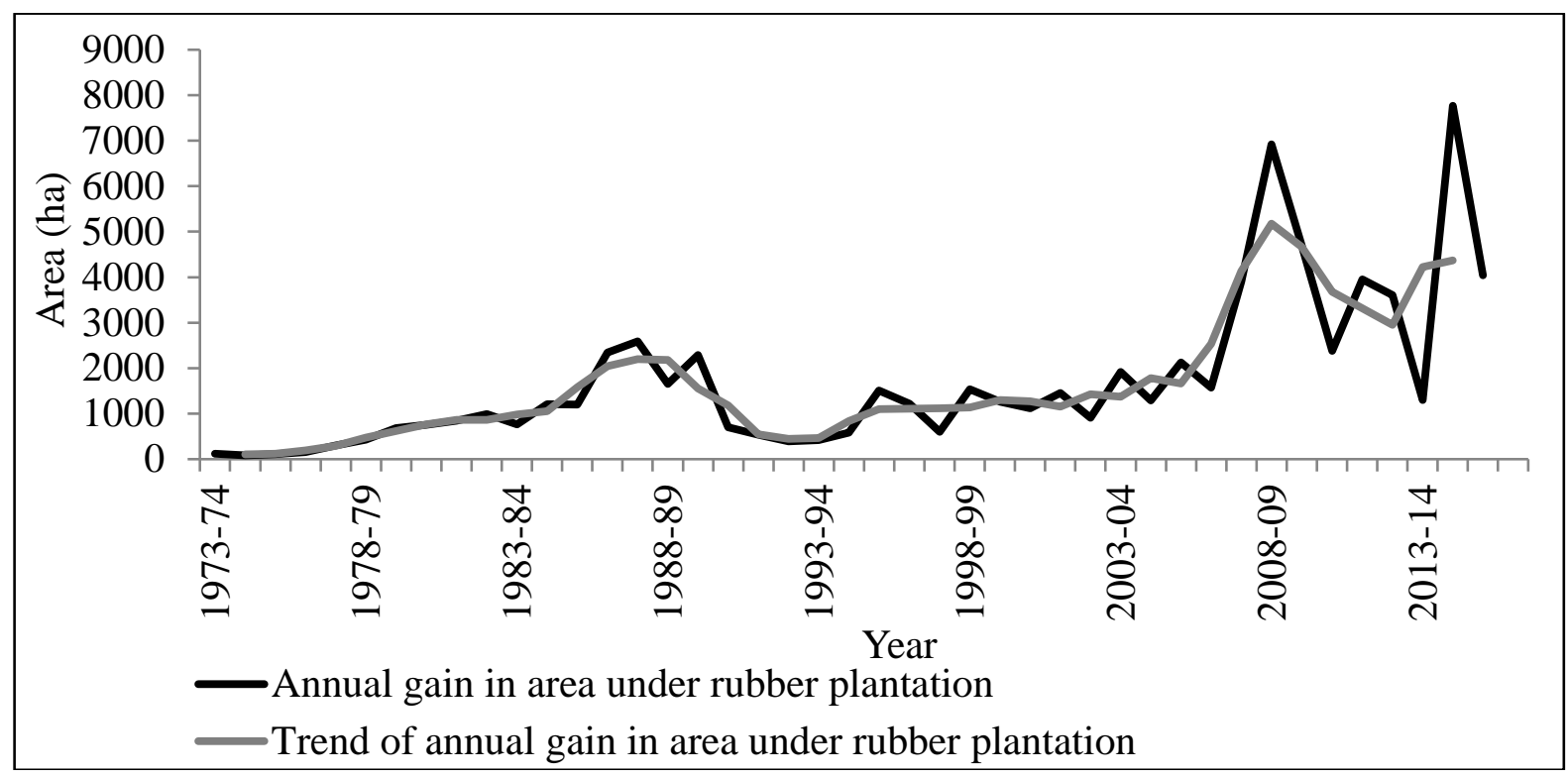

Figure 5b: Three Yearly Moving Average Trend Line and the Annual Gain in the Area under Rubber plantation in Tripura (1973-74 to 2015-16).

Source: Rubber Board, 2016; CDS, n.d (3-Year Moving Average and Annual Gain in the Area under Rubber Plantation Computed by the Authors).

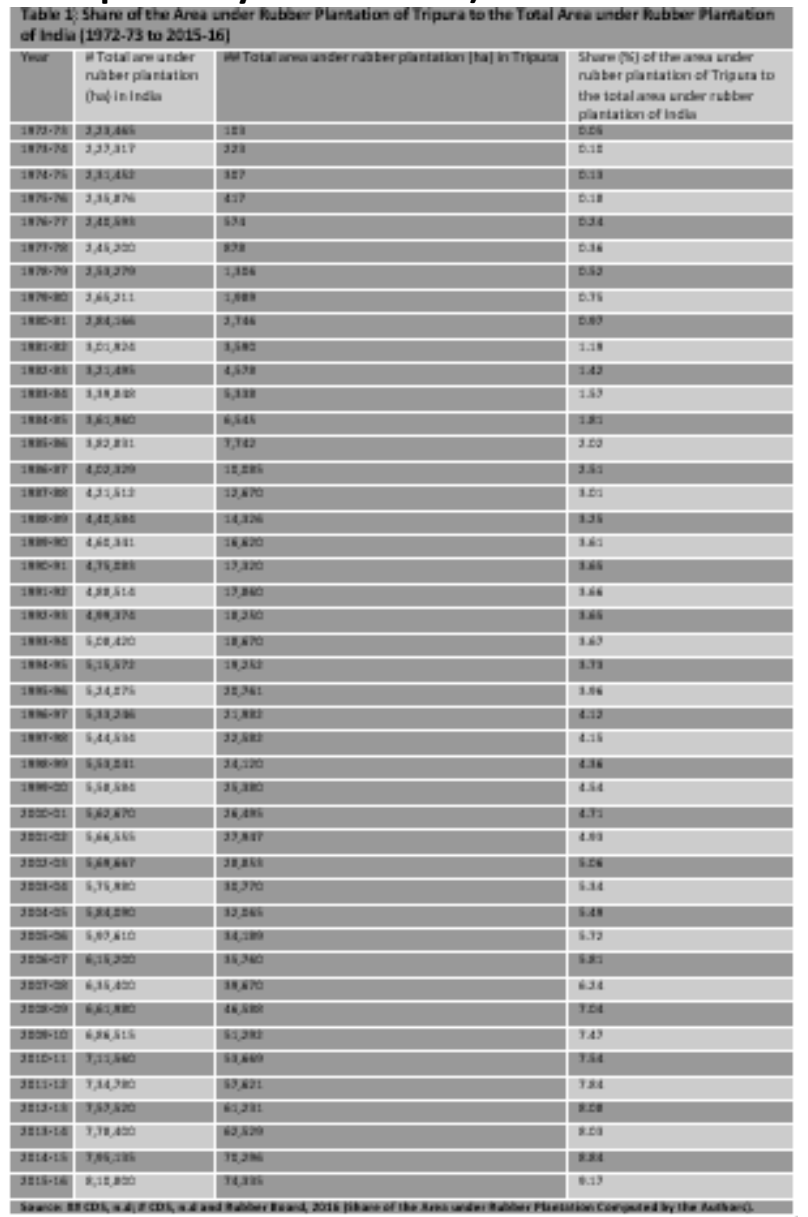




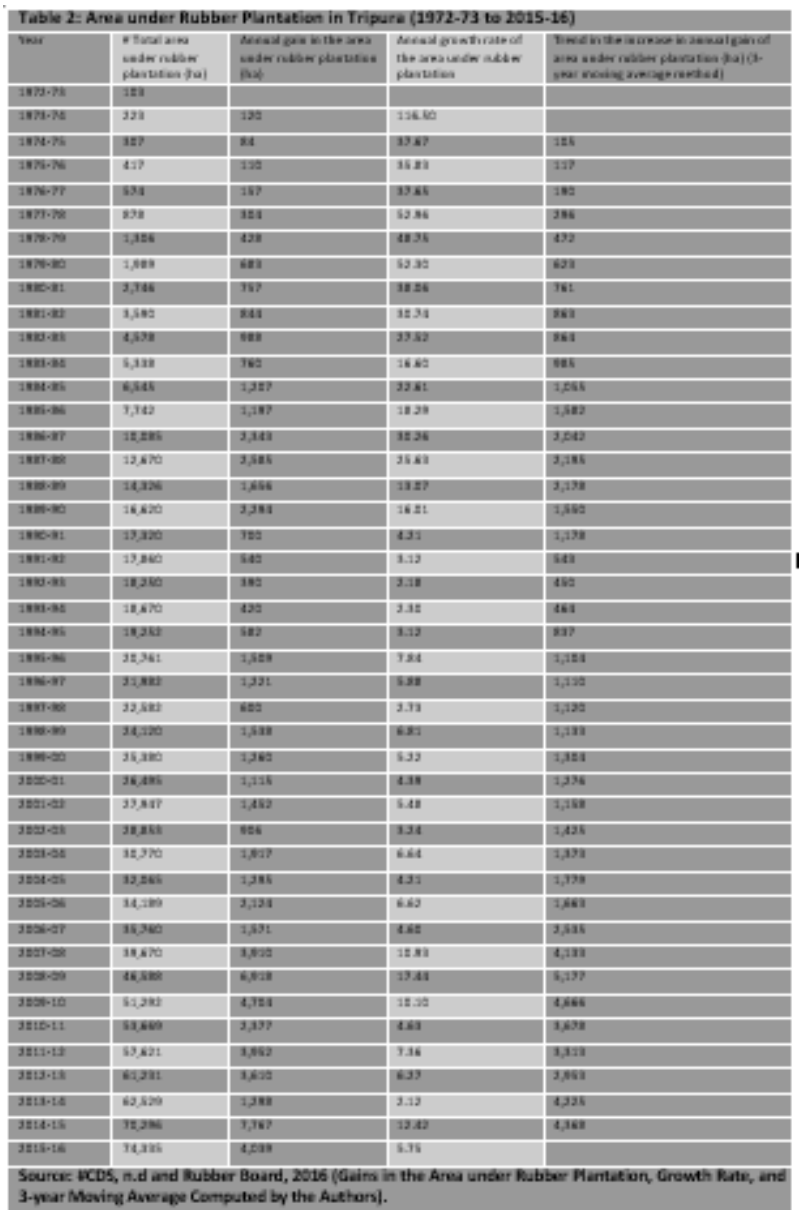

The Present Distribution Pattern of the Area under Rubber Plantation in Tripura

Table 3 suggests the district wise distribution of rubber plantation in the state of Tripura for the year 2015-16. The Table suggests that rubber plantation has spread throughout the districts of the state with West Tripura district having the highest share of the area under rubber plantation (23.71\%). This is closely followed by Sepahijala district (22.66 \%) and South Tripura district $(20.79 \%)$ while Unokoti district has the least share of the area under rubber plantation with just 3.53 per cent. Of the eight districts, it is noticed that the North Tripura, Unokoti, Dhalai, Khowai and Gomati districts have a share of less than 10 per cent each to the total area under rubber plantation of the state.

The concentration index score (Table 3 ) and its mapping (Figure 6a) suggest that the high concentration of area under rubber plantation is observed in West Tripura and Shepahijala districts. Moderate concentration is observed in South Tripura district while low concentration is observed in North Tripura, Gomati and Unokoti districts. The very low concentration of area under rubber plantation is observed in Khowai and Dhalai districts. It is interesting to note that in Dhalai district (in Manu hill ranges of the district as cited by Bhowmik, 2006; Viswanathan and Bhowmik, 2014), the first rubber plantation was introduced on an experimental basis to check soil erosion and deforestation way back in 1963-64, yet at present, this district reports the least area under rubber plantation in spite of the fact that this district has the highest share of ST population (that is, $55.68 \%$ as per Census of India, 2011) in the state.

\section{Factors Affecting the Distribution of Area under Rubber Plantation}

The maximum area under rubber plantation in West Tripura, Shepahijala and South Tripura districts can be attributed to favourable conditions like availability of land suitable for rubber plantation, better accessibility, enthusiasm among the people and policy intervention by the state administration. 
Bhattacharyya et al., (1998) highlights that the moderately suitable areas for rubber plantation in the state of Tripura are mostly characterised by undulating plains and uplands and also suggests that topography with less than 15 per cent slope is considered ideal for rubber plantation. They mention that though in steep slopes (greater than 30-50 per cent) rubber plantation can be set up, it calls for proper conservation measures as steep slopes are prone to erosion. Raj et al. (2012) state that the undulating terrain comprising of low to medium/gentle slope are ideal for rubber plantation and remarks that rubber plantation in steep slopes of Tripura has been set up with conservation measures like contour bunds.

\begin{tabular}{l|l|l|l|}
\hline \multicolumn{3}{|l}{ Table 3: District Wise Distribution of Area under Rubber Plantation in Tripura (2015-16) } \\
\hline District & Area (ha) & Area (\%) & Concentration Index Score \\
\hline North Tripura & 7,134 & 9.60 & 0.70 \\
\hline Unokoti & 2,625 & 3.53 & 0.69 \\
\hline Dhalai & 4,230 & 5.69 & 0.25 \\
\hline Khowai & 3,008 & 4.05 & 0.42 \\
\hline West Tripura & 17,625 & 23.71 & 2.64 \\
\hline Sepahijala & 16,846 & 22.66 & 2.27 \\
\hline Gomati & 7,416 & 9.98 & 0.63 \\
\hline South Tripura & 15,451 & 20.79 & 1.42 \\
\hline Total & 74,335 & 100 & \\
\hline Source: & & & \\
\hline
\end{tabular}

Source: Rubber Board, 2016(Area in \% and Concentration Index Computed by the Authors).

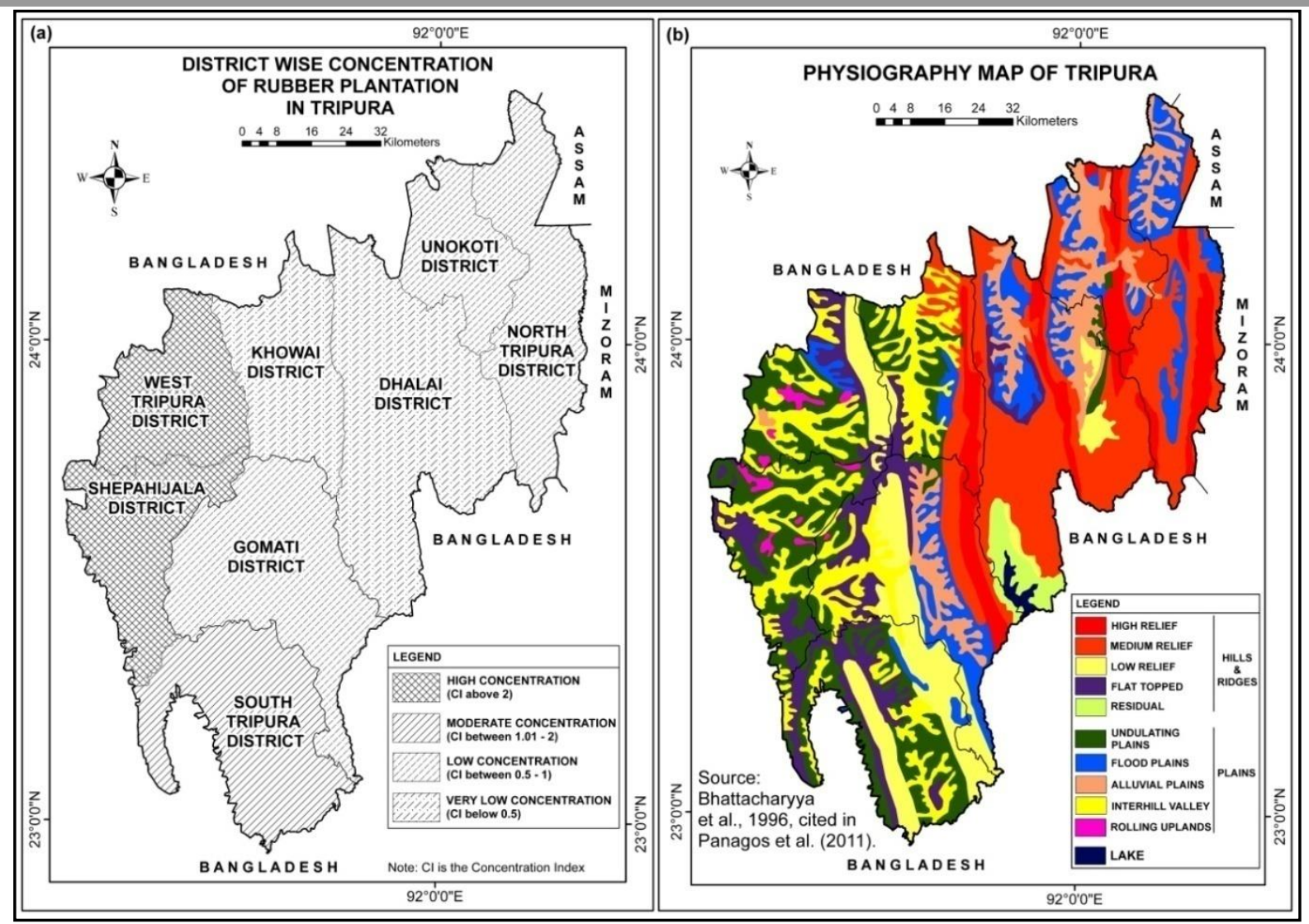

Figure 6: (a) District wise Concentration of Rubber Plantation in Tripura, 6: (b) Physiography of Tripura Sources: a) Directorate of Land Records and Settlement, 2016 (Concentration of Rubber Plantation Computed by the Authors); (b) Bhattacharyya et al., 1996, cited in Panagos et al., 2011.

Figure $6 \mathrm{~b}$ suggests that undulating topography, interspaced by valleys characterise most of West Tripura, Sepahijala and South Tripura districts and the rolling uplands are ideal for rubber plantation; plus the flat-topped topographic features found here are also considered suitable 
for rubber plantation. The districts reporting low concentration of rubber plantation can be attributed to its topographic conditions marked by steep slope (Figure 6b) with large forest coverage; as in Tripura rubber plantation is not encouraged in forested areas \{Tripura Rehabilitation and Plantation Corporation Limited (TRPCL), 2012 \& 2016; Raj et al., 2012\}. As per the directive of the Ministry of Environment, Government of India in 2005, cultivation of rubber trees are banned in reserved forests (Mohanakumar, 2013). Bhattacharyya et al., (1998) suggests that rubber plantation faces severe limitation not only in the steep slopes but also in the valleys as they are prone to water stagnation and rubber trees need well-drained soil condition. Thus, the distribution pattern suggests that the highest concentration of rubber plantation is guided by suitable physiography, soil and other agroclimatic conditions.

\section{Conclusion}

The area under rubber plantation has been increasing continuously and spreading throughout the state covering all the districts of Tripura. At present, secondary data suggests that an increase in the area under rubber plantation in the state is growing at a declining rate often fluctuating. Rubber plantations are mostly concentrated in West Tripura, Sepahijala and South Tripura districts due to its physiography and other agro-climatic conditions. Besides the favourable climatic conditions, soil and physiography, effective government policies (through rubber plantationbased rehabilitation programme implemented by different agencies) and the acceptance of rubber plantation by the marginalised section of rural population as well as the private sector and individuals, has made Tripura emerge as an important producer of natural rubber, second only to Kerala in the country. Rubber plantation is highly successful in comparison to other plantation crop introduced in Tripura. Consequently, the area under rubber plantation in the state is increasing and there is scope for further expansion.

\section{References}

Abdullah, S.A. and Nakagoshi, N. (2006). Changes in landscape spatial pattern in the highly developing state of Selangor, Peninsular Malaysia, Landscape and Urban Planning 77, pp. 263-275.

Bhattacharyya, T., Sehgal, J. and Sarkar, D. (1996). Soils of Tripura for optimizing land use: their kinds, distribution and suitability for major field crops and rubber, NBSS Publication 65b (Soils of India series 6), NBSS \& LUP, Nagpur, India, pp. 1-14.

Bhattacharyya, T., Sarkar, D., Gangopadhyay, S.K., Dubey, P.N., Baruah, U., Chamuah, G.S., Mukhopadhyay, S., Nayak, D.C., Maji, A.K., Saxena, R.K., Barthwal, A.K., Krishna, N.D.R., Mandal, C. and Sahgal, J. (1998). Soils of Tripura.Il- Suitability for Rubber, Agropedology, 8, pp. 55-60.

Bhowmik, I. (2006). A status on Rubber Plantations in Tripura, Tripura Rubber Mission- Technical Bulletin, pp. 1-21.

Census of India (2011). 2011 census dataPopulation Enumeration Data, Office of the Registrar General and Census Commissioner, India, New Delhi. Available at http://www.censusindia.gov.in/2011census /population_enumeration.html (accessed February 04, 2018).

Centre for Development Studies (n.d). Area under rubber and average yield per hectare. Available at http://cds.edu/research/ru/nrppd/databas e-on-plantation/rubber/ (accessed January 23, 2018).

Chaudhuri, P.S., Bhattacharjee, S., Dey, A., Chattopadhyay, S. and Bhattacharya, D. (2013). Impact of age of rubber (Hevea brasiliensis) plantation on earthworm communities of West Tripura (India), Journal of Environmental Biology, Vol. 34, pp. 59-65.

Chen, H., Yi, Z-F., Schmidt-Vogt, D., Ahrends, A., Beckschafer, P., Kleinn, C., Ranjitkar S. and $\mathrm{Xu}$, J. (2016). Pushing the Limits: The Pattern and Dynamics of Rubber 
Monoculture Expansion in Xishuangbanna, SW China, PloS ONE 11(2), pp. 1-15.

Das, R. (2014). Rubber Plantation: Tripura Scenario. In K. Shib (eds.), Rubber in Tripura (1963 2013)- Golden Jubilee Celebration, Souvenir, Arundhatinagar, Agartala: Bina Printers, pp. 25-33.

Directorate of Economic and Statistics Planning Department (DESPD) (2016). Economic Review of Tripura (2015-16), 17 $7^{\text {th }}$ issue. Government of Tripura, Agartala, Tripura, pp. 3-239.

Directorate of Land Records and Settlement (2016). Map of Tripura. Government office, Agartala, Tripura.

East-West Center (n.d). Economic Development and Land-use Change: Expansion of Rubber Plantations in Southeast Asia. Available at https://www.eastwestcenter.org/research/ research-projects/economic-developmentand-land-use-change-expansion-cash-cropsin-southeas (accessed October 7 October 2018).

Fox, J. and Castella, J.C. (2013). Expansion of rubber (Hevea brasiliensis) in Mainland Southeast Asia: What are the prospects for smallholders?, Journal of Peasant Studies, 40 (1), pp. 155-170.

Fox, J. and Vogler, J. (2005). Land-use and landcover change in Montane Mainland Southeast Asia, Environmental Management, 36, pp. 394-403.

Fox, J.M., Castella, J., Ziegler, A.D. and Westley, S.B. (2014). Rubber Plantations Expand in Mountainous Southeast Asia: What are the Consequences for the Environment?, AsiaPacific Issues No. 114, pp. 1-8.

Fu, Y., Brookfield, H., Guo, H., Chen, J., Chen, A. and Cui, J. (2009). Smallholder rubber plantation expansion and its impact on local livelihoods, land use and agrobiodiversity, a case study from Daka, Xishuangbanna, southwestern China, International Journal of Sustainable Development and World Ecology, Vol. 16, No.1, pp. 22-29.
Gupta, M.D. (1990a). Rehabilitating Jhumias On Rubber Plantations: An Assessment of the Tripura Experiment. In D.N. Majumdar (eds.), Shifting Cultivation in North-East India, New Delhi: Omsons Publications, pp. 308-311.

Gupta, B.N. (1990b). Statistics (Theory \& Practice). Sahitya Bhawan, Agra, pp. 312313, 515-584.

Gupta, A.K. (2000). Shifting Cultivation and Conservation of Biological Diversity in Tripura, Northeast India, Human Ecology, Vol. 28, No. 4, pp. 605-629.

Hasan, M.I. (2005). Population Geography. Jaipur, New Delhi, Bangalore, Hyderabad, Guwahati, Kolkata: Rawat Publications (ISBN: 978-81-7033-967-0).

Human Development Report (2007). Tripura Human Development Report, Government of Tripura, Tulika Print Communication Services, New Delhi.

Joseph, J., George K, T. and Dey, S.K. (2010). Report on the socio-economic impact of Natural Rubber cultivation under the block planting scheme in Tripura, MPRA Paper No. 52370, pp. 1-39.

Krishnakumar, A.K. and Meenattoor, R. J. (2003). Restoration of denuded lands in the northeastern India through rubber plantations, LEISA INDIA, pp. 23-24.

Li, Z. and Fox, JM. (2011). Mapping rubber tree growth in mainland Southeast Asia using time-series MODIS $250 \mathrm{~m}$ NDVI and statistical data, Applied Geography, 32. pp. 420-432.

Liu, W., Hu, H., Ma, Y. and Li, H. (2006). Environmental and Socioeconomic Impacts of Increasing Rubber Plantations in Menglun Township, Southwest China, Mountain Research and Development, Vol. 26, No. 3, pp. 245-253.

Maithani, B.P. (2005). Shifting Cultivation in North-East India: Policy issues and options. New Delhi: Mittal Publication (ISBN: 8183240291). 
Mohanakumar, S. (2013). Expansion of Natural Rubber Cultivation in Tripura: Impact on Landholding, Employment and Income, NLI Research Studies Series No. 107, pp. 1-46.

Noguchi, S., Kasran, B., Yusop, Z., Tsuboyama, Y and Tani, M. (2003). Depth and Physical Properties of Soil in a Forest and a Rubber Plantation in Peninsular Malaysia, Journal of Tropical Forest Science 15 (4), pp. 513-530.

Panagos, P., Jones, A., Bosco, C. and Senthil Kumar, P.S. (2011). European digital archive on soil maps (EuDASM): preserving important soil data for public free access, International Journal of Digital Earth, 4 (5), pp. 434-443.

Raj, U., Hebbar, R., Ravishankar, H.M., Jacob, J., Ray, D., Meti, S., Shebin, S.M., \& Pradeep, B. (2012). Geospatial Technology for Acreage Estimation of Natural Rubber and Identification of Potential Areas for its Cultivation in Tripura, Project Report, Issue no. 1, National Remote Sensing Centre, ISRO, Govt. of India and Rubber Research Institute of India, Rubber Board, Min. of Commerce \& Industry, Govt. of India, pp. 145.

Rubber Board (2016). Role of Rubber Board in Growth of Rubber Plantation in NE, The regional office, Agartala.

Sarkar, S. (2011). Rubber Plantation: A new hope for rural tribals in Tripura, International Journal of Plant Sciences, Vol. 6 Issue 2, pp. 274-276.
Sharma, G., Joseph, J., George K, T. and Dey, S.K. (2011). Impact of Mahatma Gandhi National Rural Employment Guarantee Act on Rubber Block Plantation Scheme in Tripura, Agriculture Economic Research Review Vol. 24, pp. 525-530.

Survey of India (n.d). Political Map of India 2017. Available at www.surveyofindia.gov.in (accessed January 23, 2018).

Tripura Rehabilitation and Plantation Corporation Limited (TRPCL) (2012). Brief Note on Tripura Rehabilitation Plantation Corporation Ltd. Diary 2012, Government of Tripura, Agartala, Tripura, pp. 1-12.

TRPCL (2016). Documents on Tripura Rehabilitation Plantation Corporation Limited, Agartala, Tripura.

Verheye, W. (2010). Growth and Production of Rubber. In Verheye, W. (ed.), Land Use, Land Cover and Soil Sciences, Encyclopedia of Life Support Systems (EOLSS), UNESCO-EOLSS Publishers, Oxford, UK. pp. 1-20.

Viswanathan, P.K. and Bhowmik, I. (2014). Compatibility of Institutional Architecture for Rubber Plantation Development in North East India from the Comparative Perspective of Kerala, NRPPD Discussion Paper No. 38, Centre For Development Studies, Thiruvananthapuram, pp. 1-71.

\section{Acknowledgements}

The author(s) acknowledge the Rubber Board, Agartala, for the support and help in providing the necessary data and information regarding rubber plantation in the state of Tripura. 